A R T I G O

\title{
AS VOZES DA MEMÓRIA EMPRESARIAL: A EXPERIÊNCIA DO GRUPO GLOBO
}

\author{
The Voices of Corporate Memory: The Experience of Grupo Globo
}

Las voces de la Memoria Empresarial: la Experiencia de Grupo Globo

\author{
SILVIA FIUZA ${ }^{\mathrm{I}^{*}}$ \\ ANA PAUla GOULART RIBEIRO ${ }^{I * *}$
}

https://doi.org/10.1590/S2178-149420210306

'Grupo Globo - Rio de Janeiro (RJ), Brasil.

*Doutora em História da Cultura pela Pontifícia Universidade Católica do Rio de Janeiro (silvia.fiuza@g.globo)

"Universidade Federal do Rio de Janeiro - Rio de Janeiro (RJ), Brasil.

**Doutora em Comunicação pela Escola de Comunicação da Universidade Federal do Rio de Janeiro

(goulartap@gmail.com)

(D) https://orcid.org/0000-0002-9341-4629

Artigo recebido em 27 de abril de 2021 e aprovado para publicação em 09 de julho de 2021. 


\section{RESUMO}

0 artigo propõe discutir a experiência de história oral realizada no âmbito das áreas de memória das empresas brasileiras, em especial no Grupo Globo. Nesse contexto, a história oral é um rico meio que permite, por meio dos elementos subjetivos da memória individual, produzir inteligibilidade sobre processos institucionais e sociais mais amplos. Destacamos três aspectos essenciais: a seletividade e o enquadramento da memória; a existência de unidades narrativas que sintetizam experiências e ajudam a compreender os acontecimentos; e a sinergia entre produções audiovisuais e narrativas de história oral.

PALAVRAS-CHAVE: Memória; História; História Oral; Memória Empresarial; Grupo Globo; Comunicação.

\section{Abstract}

The paper discusses the experience of oral history carried out within the scope of the memory areas of Brazilian companies, especially Grupo Globo. In this context, oral history is an important tool that allows, through the subjective elements of individual memory, to produce intelligibility about wider institutional and social processes. Three specific aspects will be highlighted: selectivity and the framing of memory; the existence of narrative units that synthesize experiences and help to understand events; and the synergy between audiovisual productions and oral history narratives.

KEYWORDS: Memory; History; Oral History; Corporate Memory; Grupo Globo; Communication.

\section{RESUMEN}

El artículo tiene como objetivo discutir la experiencia de la historia oral en el campo de la memoria de las empresas brasileñas, especialmente del Grupo Globo. En este contexto, la historia oral es un instrumento rico que permite, a través de los elementos subjetivos de la memoria individual, hacer inteligibles los procesos institucionales y sociales más amplios. Destacamos tres aspectos esenciales: selectividad y encuadre de la memoria; la existencia de unidades narrativas que sintetizan experiencias y ayudan a comprender los acontecimientos; y la sinergia entre producciones audiovisuales y narrativas de historia oral.

PALABRAS CLAVE: Memoria; Historia; Historia Oral; Memoria Empresarial; Grupo Globo; Comunicación. 
$\mathrm{O}$ s conceitos de história e memória sempre foram, tradicionalmente, vistos em oposição um ao outro, tanto no campo da pesquisa histórica quanto no dos estudos de memória. Fosse para exaltar a primeira como uma elaboração impessoal e crítica, fosse para celebrar a segunda como o espaço da experiência viva e dinâmica, os dois termos eram contrapostos um ao outro. Em defesa da memória, o sociólogo Maurice Halbwachs (1990: 74) chegou a comparar a história a um cemitério: uma representação do passado tão esquemática, fria e vazia de sentido quanto a maioria das inscrições de túmulos. O historiador Marc Bloch (1998: 231), por sua vez, enfatizou a maleabilidade da memória e chamou atenção para a possibilidade de erros, enganos e falsas recordações.

Essa discussão é longa e não caberia aqui retomá-la. Foi reconfigurada ao longo do tempo, ganhando novas formas e argumentos. Entretanto, certa desconfiança em relação à memória - e aos relatos orais - quase sempre expressou a posição de historiadores. Isso começou a mudar nas décadas de 1970 e 1980, com a emergência da chamada cultura da memória (Huyssen, 2000), caracterizada por uma forte valorização das práticas mnemônicas relativas tanto ao patrimônio histórico em geral quanto à indústria do consumo e do entretenimento. Foi o período também da virada subjetiva (Sarlo, 2007) e do fortalecimento dos testemunhos (Wieviorka, 1995), acompanhados da constituição de diversos programas de história oral em instituições acadêmicas, empresas e comunidades variadas.

A emergência da memória no discurso histórico foi desdobramento desse contexto. Seus marcos simbólicos foram a consolidação e a institucionalização da História Oral e de uma nova forma de entender o contemporâneo, com a criação do Instituto de História do Tempo Presente na França, em 1978. Hoje, como lembra Kerwin Lee Klein (2000: 128), a declaração de que a história e a memória não são, de fato, opostas tornou-se uma espécie de cliché que aponta para novas configurações da imaginação histórica e da consciência mnemônica.

Philippe Joutard $(2007,2015)$ talvez seja um dos que mais enfaticamente tem defendido a conciliação da história com a memória. Entre seus vários argumentos, está a necessidade de que ambos os campos reconheçam seus limites e entendam que suas aproximações em relação ao passado são sempre parciais. A memória não é, claro, o mesmo que história, mas deve necessariamente ser um de seus objetos. Ela previne a história contra a tentação do determinismo e fornece-lhe o "vínculo carnal" de que precisa para tornar o passado inteligível. $E$, nesse sentido, os relatos orais são essenciais.

A subjetividade dos testemunhos tem sido, geralmente, um dos principais motivos da desconfiança de alguns historiadores em relação à história oral. Essa mesma característica, entretanto, também é indicada por outros como sua maior potencialidade. Somente por meio da subjetividade alguns fenômenos podem se tornar inteligíveis e se transformar em repre- 
sentações capazes de atuar na realidade. A entrevista é uma forma de acessar a memória, possibilitando ao entrevistado reviver fragmentos do passado no presente. Ao fazer o trabaIho de memória, ele aciona ferramentas de seleção, organização e enquadramento do que é rememorado. Na condução da entrevista, o entrevistador, mesmo que comedido em suas intervenções, também opta por certos caminhos em detrimento de outros possíveis.

Alberti (2004: 33) chama atenção para o fato de que, na história oral, entram em cena formas de "negociar e disputar significados e desencadear ações". A autora lembra que numa entrevista estão em jogo, ao mesmo tempo, um relato do passado e um resíduo de ações desencadeadas na própria entrevista. Ambos são resultado da interação entre entrevistado e entrevistador, de um trabalho dialógico de interpretação e reconstrução (Arfuch, 1995). A história oral permite identificar como os acontecimentos são elaborados no presente por meio de enquadramentos, esquecimentos e silenciamentos que revelam negociações e disputas pelo sentido do passado (Pollak, 1989, 1992).

Como assinala Portelli (2006: 111), "talvez essa interação seja o campo específico da história oral, que é contabilizada como história com fatos reconstruídos, mas também apreende, em sua prática de trabalho de campo dialógico e na confrontação crítica com a alteridade dos narradores, a entender as representações". A especificidade e a riqueza da história oral residem exatamente aí: tanto no fato de ela ser território fértil para o estudo da subjetividade e das representações do passado quanto dotada de elementos capazes de agir sobre a realidade e de compreender esse passado (Alberti, 2004: 42).

A história oral, mais do que fornecer pistas para acessar o passado, produz narrativas no presente que permitem uma forma de aproximação com a realidade. Transforma lembranças, experiências e acontecimentos em linguagem e, além de produzir uma "versão" dos acontecimentos, fornece uma chave para sua compreensão. Alberti (2004: 79) denomina de "unidades indivisíveis do acontecimento" aqueles fatos que encerram sentido na atividade de condensar e comunicar experiências por meio do trabalho de linguagem. Cabe ao pesquisador identificar as unidades narrativas capazes de comunicar realidades que ultrapassam as trajetórias particulares e ajudam a compreender contextos sociais, culturais, profissionais, geracionais.

\section{A HISTÓRIA ORAL EM CENTROS DE MEMÓRIA EMPRESARIAL}

as últimas décadas, tem aumentado o número de arquivos orais criados em centros
de memória, institutos e museus empresariais. No Brasil, há mais de 20 anos, grandes empresas - como Globo, Votorantim, Klabin, Petrobras, Banco Nacional de Desenvolvimento Econômico e Social (BNDES) e Vale do Rio Doce — desenvolvem ou já desenvolveram progra- 
mas desse tipo. 0 mesmo acontece com fundações e institutos vinculados a empresas, como a Memória da Eletricidade, a Fundação Bunge e a Fundação Energia e Saneamento. Também instituições acadêmicas com forte atuação no campo da história oral, como o Centro de Pesquisa e Documentação de História da Fundação Getulio Vargas (CPDOC/FGV), desenvolvem projetos ligados ao universo empresarial (Alberti, 1996). E, cada vez mais, surgem empresas especializadas em oferecer serviços e implantar programas de entrevistas em outras empresas, como Grifo, Tempo e Memória, Museu da Pessoa e Memória \& Identidade.

Esses programas de história oral são montados tendo em vista a trajetória da empresa e de seus fundadores. Na maioria dos casos, há também um trabalho arquivístico e de pesquisa com documentos textuais, iconográficos, audiovisuais e tridimensionais. As entrevistas são feitas com colaboradores e ex-colaboradores e conduzidas por profissionais com formação variadas. São historiadores, antropólogos, jornalistas, bibliotecários e arquivistas que atuam em departamentos de memória na própria empresa ou são terceirizados. Esses projetos integram uma proposta mais ampla de valorização da história da empresa como instrumento para a construção de sua identidade e para a produção de diferentes formas de comunicação interna e externa.

É importante observar que a história oral nas empresas, como em qualquer outra instituição, pressupõe um trabalho de produção da fonte histórica. 0 entrevistador tem um papel especialmente ativo na fabricação do registro. Não só coleta dados ou informações guardadas ou acumuladas por um terceiro (indivíduo, grupo ou instituição); ele participa do ato criador desses dados e informações. E o resultado do seu trabalho pode se desdobrar em ações e produtos os mais variados. As entrevistas podem ser usadas na obtenção de dados sobre 0 passado inexistentes em documentos de outra natureza. Ajudam a recuperar informações sobre fatos e processos que só podem ser conhecidos pela narrativa daqueles que os viveram direta ou indiretamente.

No caso do Grupo Globo, como se trabalha com a metodologia de história de vida, as entrevistas formam um conjunto extremamente importante para a compreensão da dinâmica de funcionamento não apenas das empresas do grupo mas de outros órgãos de informação do país, dos meios de comunicação como um todo e mesmo de outros circuitos da produção cultural, como o cinema, por exemplo. Os depoentes, antes ou depois de falarem de suas vivências na Globo, comentam — às vezes, com riqueza de detalhes - diversas outras experiências profissionais e de vida. Atores e atrizes falam sobre momentos marcantes da história do teatro e contam sobre as formas de produção nos tempos pioneiros da televisão ao vivo. Além disso, são muitos os aspectos abordados: estéticos, tecnológicos, discursivos, editoriais, econômicos, culturais e políticos. 
Ainda que possam se constituir em fonte preciosa para as empresas sobre dados e processos do seu passado, os depoimentos orais não podem ser tratados como indicadores absolutos da verdade histórica. Ao produzir e, posteriormente, trabalhar com as entrevistas, é necessário se levar em conta - como já mencionamos - as subjetividades envolvidas e o trabalho de linguagem e enquadramento da memória realizado no contexto da entrevista. A memória é um ato criativo potente, no qual a imaginação exerce um papel determinante (Keightley e Pickering, 2012). Está em constante reelaboração com base nos contextos sociais e nas circunstâncias concretas de interação humana.

É essencial que os depoimentos não sejam trabalhados isoladamente, mas que componham painéis vastos e variados, que remetam a experiências plurais e múltiplas. Um projeto como o do Grupo Globo, de montar um programa de história oral com a consequente criação de um arquivo de depoimentos, alinha-se a essa ideia. A proposta é ouvir, ao lado das personalidades e grandes lideranças (gestores ou profissionais de destaque), os relatos de colaboradores "comuns", que testemunharam os fatos e os processos sob diferentes perspectivas.

Não só na Globo, mas nas empresas em geral, as entrevistas compõem um acervo de depoimentos gravados em áudio e/ou em vídeo, transcritos e organizados em bancos de dados e imagens. São usados em produtos culturais (exposições, sites, publicações, documentários, museus) e em ações internas como a produção de balanços sociais, treinamentos e comemorações do aniversário da empresa. Mas existem outros "usos" menos tangíveis e que fazem parte do próprio processo de construção da entrevista de história oral.

Na história oral, entrevistado e entrevistador constroem, conjuntamente, uma interação na qual cada um ocupa uma posição dupla. Embora exista um compromisso em relação aos episódios objetivos da trajetória, a subjetividade é uma peça inerente à construção da narrativa. Para ambos, o que está em jogo é o percurso da vida do entrevistado, sempre mesclado a sentimentos, emoções e sensações. 0 entrevistador envolve-se em todo o processo, da formulação das perguntas à condução da fala, reagindo aos silêncios, lapsos, hesitações e divagações do depoente.

Sob esse ponto de vista, a entrevista pode lembrar alguns aspectos de uma sessão de psicanálise. A interação estabelecida vai na linha da intersubjetividade assinalada por Alfred Schutz (1979). É uma interação sujeita ao olhar do pesquisador, que pode adotar diferentes ângulos e assumir diferentes posições (mais próximas ou distanciadas) na busca pela subjetividade do outro, por suas visões e concepções da realidade, seus projetos, suas motivações e inserções nos múltiplos mundos sociais em que transita.

É possível também aproximar a história oral do contexto da pesquisa antropológica. Estão em cena múltiplas interpretações e leituras de uma certa realidade que, por mais que seja familiar ao investigador, deve lhe causar algum estranhamento, um pouco na direção do 
estrangeiro simmeliano, que se mantém exterior, não busca a assimilação nem a identificação total. Seu pertencimento dá-se numa interação que supõe, ao mesmo tempo, proximidade e distanciamento, familiaridade e estranhamento. E cabe a ele, mesmo consciente de que a "realidade" apresentada é filtrada pelo seu ponto de vista, trazer à superfície elementos que traduzem a biografia e a vida social descrita. Ao analisar o conteúdo, ele deve buscar uma "descrição densa" da realidade apresentada, tendo em vista que o que se constrói é uma interpretação; o que se interpreta é o fluxo do discurso social, identificando o "dito" para fixá-lo em formas pesquisáveis (Geertz, 1978: 31).

Entrevistado e entrevistador têm consciência de que o relato constitui uma fonte histórica e buscam dar alguma racionalidade ao discurso produzido no contexto de interação. 0 entrevistado seleciona e condensa os acontecimentos de modo a fornecer coerência ao seu relato. Já o entrevistador está na entrevista porque, a priori, ela constitui uma fonte para 0 seu trabalho. Essa é sua motivação principal. Para isso, ele monta um roteiro de perguntas, selecionando fatos e momentos significativos na história do entrevistado, e busca também coerência na construção de roteiros, na eleição de perguntas, na indicação de dados adicionais ou na forma como alinha as novas informações recebidas durante a entrevista. Tanto entrevistado quanto entrevistador realizam um trabalho de memória, que se dá por seleção (esquecimento ou silenciamento) e por enquadramento (Pollak, 1992).

No caso da história oral em um centro de memória empresarial, há um terceiro elemento presente: a história da empresa. Quando uma organização se propõe a incentivar um projeto desse tipo, com os acionistas, executivos e/ou colaboradores, há a intenção institucional de buscar elementos que contribuam para o reforço do sentimento de pertencimento no interior da empresa e para a construção da sua identidade, valores e reputação. Na entrevista, trabalha-se a trajetória da empresa paralelamente à do entrevistado, e em muitos momentos essas dimensões se entrecruzam e se confundem.

Já na produção dos roteiros, o entrevistador seleciona previamente um conjunto de eventos como representativos e tenta estabelecer os parâmetros sob os quais o trabalho da memória do outro vai se dar. Cabe a ele não só trazer diferentes elementos para o contexto da entrevista, mas também zelar para que eles não eliminem ou direcionem informações relevantes dadas pelos entrevistados. Portanto, a memória revelada no contexto da história oral não só sofre os efeitos da seletividade e dos enquadramentos, como também põe em negociação e mesmo em disputa as memórias do entrevistador (configuradas pela perspectiva da empresa) e as do entrevistado.

Cabe ao entrevistador conter o impulso de conciliar essas memórias. Ao contrário, ele deve trazê-las à superfície, buscar, como defende Alberti (2004: 110), as unidades narrativas que condensam experiências representativas para compreender não só formas específicas de 
elaborar os acontecimentos, mas também pistas significativas para dialogar com outras fontes. Esse trabalho crítico feito durante a entrevista e em análise posterior permite ao pesquisador se aproximar do que é verossímil (ou não) e construir interpretações com base nos relatos.

As facilidades das novas tecnologias ajudaram na consolidação da história oral nas empresas. Até o surgimento do gravador, os depoimentos eram anotados e transformados em documento escrito. Com a possibilidade de registrar o áudio e, posteriormente, a imagem em vídeo, foi possível realizar o trabalho simultâneo de capturar narrativas sobre os acontecimentos e registrar gestos, silêncios, reações, hesitações, lapsos. Com o desenvolvimento da imagem e do áudio digitais, bem como das redes informatizadas que facilitam a indexação e a localização dos conteúdos dos acervos, tornou-se mais fácil analisar as informações e o trabalho de linguagem na história oral. É preciso, por outro lado, considerar que as tecnologias são, elas próprias, um ator no contexto da entrevista e mesmo na sua posterior organização e análise.

Inibições, hesitações ao relatar episódios traumáticos; omissões de detalhes sobre fatos cuja divulgação tende a causar embates; bloqueios ao citar casos que envolvem pessoas próximas; desgaste emocional; tudo isso ocorre nas situações de entrevista, e o pacto entre entrevistador e entrevistado pode a qualquer momento se fragilizar. Cabe ao entrevistador estar em permanente vigília. Ao perceber que há risco de perder qualidade e credibilidade, ele deve analisar a possibilidade de mudanças de rumo ou mesmo de interrupção da entrevista para continuação em outro momento (Joutard, 2000: 41).

A entrevista de história oral tem uma "moldura" que dá suporte à sociabilidade entre os seus participantes e ao envolvimento subjetivo na experiência. Essa moldura é constituída dos princípios que governam a experiência social dos indivíduos e que permitem uma interação sem risco de desencontros e conflitos. Ela organiza o envolvimento dos participantes ao fornecer as compreensões básicas da comunicação entre os sujeitos. A quebra da moldura pode produzir uma "experiência negativa", desorientação e perda de referências (Goffman, 2012).

Há de se ter outros cuidados: preparar-se para a entrevista, pesquisando e identificando momentos-chave da trajetória do entrevistado e, se possível, buscando informações sobre aspectos mais pessoais, como facilidade em falar publicamente, timidez, cautela e prudência. Na entrevista, é importante estabelecer um relacionamento de confiança com o entrevistado; minimizar a presença do equipamento de gravação, de modo que ele fique mais relaxado; agir com segurança diante de defeitos em equipamentos, barulhos e interrupções externas; ouvir e fazer perguntas abertas, sempre evitando induzir respostas; frear os impulsos de interromper o entrevistado e, quando necessário, aguardá-lo completar o pensamento; permitir pausas, silêncios e digressões, retornando ao assunto assim que possível; evitar ser inquisitivo e não usar jargões. 
Esses são parâmetros gerais válidos para a história oral como um todo, também no ambiente empresarial. Mas é importante ter em mente que não existe uma fórmula para as entrevistas. Elas são sempre únicas, inseridas em culturas e relações de comunicação singulares. São encontros entre entrevistado e entrevistador que ocorrem num dado tempo, local e circunstância específicos. Cada encontro implica um pacto e a construção de certa confiança e intimidade: 0 depoente está ali rememorando sua vida e seus acontecimentos significativos; o entrevistador, entregue integralmente ao protagonismo do outro, subordina-lhe sua escuta e sua fala.

Em empresas, como a Globo, há ainda outra questão a ser levada em conta. Pessoas pertencentes a ambientes profissionais que privilegiam a expressão verbal tendem a ter maior domínio na articulação das respostas e nas formulações de pensamento durante a entrevista. Isso acontece com categorias profissionais como jornalistas, autores, atores, apresentadores de televisão. Seu repertório comunicativo tem forte ancoragem na palavra, na "arte do bem dizer", na retórica argumentativa, na eloquência com que defendem suas versões e seus pontos de vista. Seu raciocínio e a linguagem persuasiva, por um lado, podem facilitar o desenvolvimento da entrevista, mas, por outro, demandam cuidados suplementares para que 0 entrevistado não perca seu papel ativo. Além disso, jornalistas, atores e outros profissionais da mídia estão acostumados a condensar e editar narrativas. Isso faz com que fique mais evidente a seletividade e o enquadramento de suas memórias. Cabe ao entrevistador perceber esses aspectos e, usando outras fontes previamente pesquisadas, tentar ampliar a narrativa e desconstruir posições previamente cristalizadas.

A opção por trabalhar com a metodologia de história de vida traz reflexões adicionais. Em primeiro lugar, é preciso sempre ter em mente que entrevistado e entrevistador, por mais que possam ter consciência da singularidade de cada entrevista e da presença constante da seletividade e do enquadramento no trabalho de memória, têm a pretensão de dar algum ordenamento aos diversos acontecimentos relatados. Como salienta Bourdieu (2006: 184), investigador e investigado "tendem ou pretendem organizar-se em sequências ordenadas segundo relações inteligíveis". Ambos têm de certa forma "o mesmo interesse em aceitar o postulado do sentido da existência narrada". É impossível compreender uma biografia sem ter em vista a superfície social sobre a qual ela se desenrola, isto é, "sem que tenhamos previamente construído os estados sucessivos do campo no qual ela se desenrolou e, logo, o conjunto das relações objetivas que reuniram o agente considerado [...] ao conjunto dos outros agentes envolvidos no mesmo campo e confrontados com o mesmo espaço dos possíveis" (Bourdieu, 2006: 190).

0 alerta é importante porque, na história oral, tanto os acontecimentos selecionados pelo depoente quanto as interpretações do pesquisador durante a entrevista e em análise pos- 
terior devem ser problematizados porque o que está em jogo são certos sentidos entre muitos outros possíveis. Isso, obviamente, não descredita a história oral, mas aponta para a necessidade constante de contextualização das entrevistas e comparação com outras fontes (e mesmo com outras entrevistas). Demanda, ainda, especial atenção ao trabalho de linguagem realizado.

Quem já entrevistou uma mesma pessoa mais de uma vez sabe como os sentidos propostos pelo entrevistado, para sua própria vida e para os acontecimentos nela envolvidos, podem facilmente deslizar e cambiar de um contexto a outro. Haverá sempre pontos coincidentes, divergentes ou absolutamente contraditórios. Cabe ao pesquisador identificar as "unidades indivisíveis" de que fala Alberti (2004) sem, necessariamente, eliminar as dissonâncias. Elas podem se tornar pistas para compreender um acontecimento e a forma como os sujeitos se vinculam a ele. Vale, no entanto, perguntar se essa necessidade não se aplicaria a qualquer fonte documental, e não apenas à oral. Para a análise de jornais, cartas, decretos, ações judiciais, fotografias, discursos e imagens em movimento, também não é essencial identificar a "moldura" que lhes dá determinado sentido?

Há ainda outro ponto a salientar. Nos diferentes programas de história oral, entre eles os desenvolvidos nas empresas, as entrevistas geralmente são transcritas. Essa decisão de passar do oral para o escrito implica vários problemas. 0 primeiro é que o texto escrito, por mais que busque traduzir pausas, silêncios, risos, choros, repetições, dificilmente capta gestos, emoções, expressões faciais, olhares, dados essenciais para a compreensão e a análise de uma entrevista. A subjetividade das emoções é uma das vantagens dos documentos orais em relação aos escritos e, na transcrição, muito se perde. Uma segunda questão é que nem sempre o entrevistado tem dicção clara, o que faz com que algumas transcrições precisem de várias revisões. Isso sem falar na necessária conferência de dados diante das possibilidades de falha em relação às informações factuais, como nomes, ordem dos acontecimentos e datas. As transcrições precisam ser revisadas por pesquisadores especializados nos assuntos abordados antes de serem disponibilizadas para consulta.

\section{A EXPERIÊNCIA DO GRUPO GLOBO}

$\mathrm{O}$ s meios de comunicação são veículos privilegiados para a metodologia da história oral. Por terem como matéria-prima a imagem, o áudio e o texto, lidam permanentemente com a ideia de retratar acontecimentos (reais, no caso dos jornalistas; fictícios, no caso dos atores e autores). Ou seja, faz parte do próprio "negócio" construir narrativas, lidar com as dificuldades e armadilhas postas ao se narrar um fato, ao se contar o que aconteceu ou não, de modo a passar sinceridade e autenticidade e, assim, ganhar credibilidade (Trilling, 2014). 
Dan Sipe destaca o potencial sinérgico entre a história oral e as imagens em movimento na medida em que "a oralidade não é um conceito baseado exclusivamente no som. A palavra falada está inserida em um cenário, uma situação, um contexto. As pessoas falam com linguagem corporal, expressão e tom" (apud Thomson, Frisch e Hamilton, 2005: 65). Essa sinergia entre a entrevista oral e o audiovisual dá-se não somente na possibilidade de capturar o "não dito", expresso por meio de outros sentidos, mas também porque, por intermédio da imagem, o trabalho da própria entrevista - o diálogo entre entrevistado e entrevistador - é captado.

Uma entrevista com um jornalista que viveu de perto os ataques do 11 de Setembro, em Nova York, é ilustrativa. Tudo transcorria com facilidade. 0 entrevistado mantinha o domínio da narrativa, falava com desenvoltura sobre os acontecimentos, fornecendo detalhes e fazendo análises de cada episódio. Porém, ao descrever o desabamento da segunda torre, que ocorreu logo depois de o repórter ter visto bombeiros entrarem no prédio, ele teve um leve engasgo e seus olhos lacrimejaram. Desse ponto em diante, a emoção tornou-se mais presente, a voz mudou, o corpo ficou mais relaxado e a entrevista passou a ter um tom mais pessoal. Foi um momento-chave, que permitiu compreender não só como aquele repórter cobriu um acontecimento mas também aspectos relativos à própria profissão de jornalista. Com a imagem e o áudio, o pesquisador tem à sua disposição elementos da experiência que, de outra forma, seriam intangíveis.

0 programa de história oral do Grupo Globo começou em 1999. A iniciativa fez parte do projeto de criação da área Memória Globo, que tinha como objetivo trabalhar a história dos veículos de comunicação do Grupo e a biografia dos seus fundadores — os jornalistas Roberto Marinho e seu pai, Irineu Marinho. Historiadores, antropólogos e jornalistas da Pontifícia Universidade Católica do Rio de Janeiro (PUC-Rio) e da Universidade Federal do Rio de Janeiro (UFRJ) participaram da definição dos pressupostos teóricos e metodológicos para criar a área e definir suas atividades. Desde o início, ficou evidente para os envolvidos que havia à disposição uma multiplicidade de fontes (impressas, iconográficas, sonoras e audiovisuais), organizadas em arquivos e bancos de dados das diferentes empresas. Mas também se constatou que muitos acontecimentos e experiências não haviam deixado rastros materiais. Decidiu-se, então, criar um projeto de história oral com os acionistas, executivos e colaboradores, incluindo aqueles que não tinham mais vínculo com a empresa.

Em um primeiro momento, optou-se por privilegiar pessoas que ocupavam ou que tinham ocupado posições-chave no grupo, assim como colaboradores mais velhos. A motivação inicial era compreender como as empresas haviam sido criadas, como tinham sido montadas suas estruturas organizacionais, quais os seus momentos mais representativos, seus maiores 
desafios, os valores e princípios que haviam norteado cada decisão, as percepções, os sentimentos e os desejos daqueles que, de diferentes maneiras, tinham feito parte da história das empresas Globo.

Logo se percebeu que a história oral criava um leque muito amplo de possibilidades. O fato de as empresas serem longevas, ligadas ao ramo da comunicação — jornal, rádio, editora, televisão aberta, televisão por assinatura, internet — , possibilitou que fosse ampliado o campo de interesse: além da trajetória das instituições, tornava-se possível pensar na história de profissões ligadas ao universo da mídia. Além disso, ficou claro que as entrevistas tinham o potencial de revelar aspectos da história da empresa que nunca tinham sido objeto de reflexão e que poderiam ajudar a repensar formas de gestão e processos de trabalho, gerar novos produtos e fornecer subsídios para ações inovadoras.

A equipe foi ampliada com outros pesquisadores, além de profissionais eventuais, como cinegrafista, fotógrafo, produtor, transcritor e técnico em informática. Optou-se por gravar em estúdios existentes na empresa ou em produtoras independentes. Em poucos casos, problemas de saúde ou dificuldades de deslocamento impossibilitaram a ida do entrevistado aos estúdios e, nesses casos, gravou-se em sua casa ou em um local escolhido por ele. Essa decisão foi orientada por uma preocupação técnica com as gravações, mas também pelo desejo de obter boa qualidade para usá-las em produtos audiovisuais futuros.

0 programa de história oral foi dividido em módulos, de acordo com as categorias profissionais: executivos e administradores, jornalistas, cinegrafistas, fotógrafos, editores, locutores, diretores, produtores, técnicos e engenheiros, atores, roteiristas, autores e escritores, figurinistas, cenógrafos, humoristas, cartunistas, secretárias e assistentes administrativos, publicitários, entre outros. Em relação aos aspectos biográficos de Roberto Marinho e Irineu Marinho, optou-se por entrevistar também parentes, amigos e personalidades que conviveram com eles: escritores, jornalistas de outros veículos de comunicação, amigos, advogados e políticos.

A pesquisa documental foi de extrema importância na definição do projeto, desde a seleção dos entrevistados até a montagem dos roteiros. Cartas, certidões e outros documentos probatórios, artigos, reportagens, programas de entretenimento, fotografias, depoimentos e outras entrevistas de história oral tornaram possível compor painéis sobre os conteúdos associados à história dos meios de comunicação no Brasil, particularmente à história dos veículos Globo e à biografia dos fundadores do Grupo.

Ganhar a credibilidade e a empatia dos colaboradores no ambiente corporativo não é tarefa fácil. É preciso convencer o outro a contar sua história pessoal no meio profissional e para pessoas envolvidas com a empresa a quem ele presta ou prestou serviços. Em muitos 
casos, é necessário convencê-lo de que suas experiências têm valor e que ajudam a compreender os passos e decisões da empresa ao longo do tempo. Por mais que o centro de memória tenha certa autonomia, ele faz parte da área institucional do Grupo, com suas percepções e idiossincrasias. Isso não deve ser omitido. Afinal, trata-se de uma de suas características intrínsecas. 0 fato de ter uma "espada de Dâmocles" permanentemente apontada para suas cabeças não impede que o entrevistado e o entrevistador realizem o trabalho de rememoração com transparência. E aí não há fórmula: certas entrevistas iniciam de forma tensa, com o entrevistado explicitando que não falará sobre alguns temas. Porém, ao longo da entrevista, quando o trabalho de memória se aprofunda e aumenta a empatia entre entrevistado e entrevistador, surpreendentemente "memórias subterrâneas" (Pollak, 1992) vêm à superfície e desencadeiam uma sucessão de relatos não previstos.

Hoje existem nos arquivos de memória do Grupo Globo (que compreendem o acervo com as entrevistas voltadas para as empresas de comunicação e aquelas feitas sobre a biografia dos fundadores) cerca de 1.300 entrevistas, mais ou menos 3.500 horas gravadas. Praticamente todas foram transcritas e organizadas em sistemas que permitem a localização dos temas nelas abordados. Há um projeto, em execução, de armazená-las integralmente, com imagem e áudio, em nuvem e anexá-las às transcrições.

Essas entrevistas são trabalhadas pelos pesquisadores e usadas para diversas finalidades: produtos culturais como livros, exposições, documentários, sites. Muitas são utilizadas em programas ou matérias exibidas na televisão, em efemérides comemorativas, em obituários ou na redefinição de novos produtos. Há ainda uma busca por essas entrevistas em momentos de avaliação ou mudança de gestão, quando informações sobre a história empresarial podem embasar a tomada de decisão. Todos esses usos exigem um esforço de análise crítica.

Vamos destacar três experiências com as entrevistas de história oral do Grupo Globo. A primeira ocorreu em 2004, quando o Jornal Nacional (JN), telejornal diário da Globo, completava 35 anos. A área de memória propôs fazer um livro com os momentos mais representativos do JN, positivos e negativos, tendo como uma das fontes centrais as entrevistas realizadas. Com a concordância da direção, foram mapeados os principais acontecimentos desde 1969, com base na vasta pesquisa documental em jornais, revistas, material audiovisual, memorandos, entre outras fontes. Consultando-se o acervo de história oral foram identificadas lacunas, o que levou à realização de mais de 100 novas entrevistas. Selecionaram-se novos acontecimentos, o que determinou também outras pesquisas em fontes diversas.

Ao comparar as diferentes narrativas sobre os episódios, foi possível observar um ponto importante: aqueles que tiveram resultados considerados bem-sucedidos pela memória coletiva demonstraram versões consensuais, com poucas variações. Porém, acontecimentos 
conturbados, erros e episódios polêmicos apresentaram versões que divergiam e até mesmo se contradiziam. Isso nos fez pensar não só nos diferentes papéis e olhares de cada indivíduo em um grupo, mas no processo de seleção e enquadramento da memória. As experiências consideradas positivas seriam rememoradas com mais frequência, compartilhadas e reverenciadas como modeladoras da identidade dos grupos sociais envolvidos? E as negativas seriam mais difíceis de serem lembradas coletivamente, de serem fixadas e sedimentadas pela memória social? Será que o processo de ativar lembranças de episódios traumáticos traria à superfície com mais força a noção de indivíduo único, sujeito moral, psicológico e singular em sua visão de mundo? A experiência gerou o livro Jornal Nacional: a notícia faz história, editado pela Jorge Zahar Editora, e vendeu mais de 120 mil exemplares, um fenômeno editorial para os padrões brasileiros. Até hoje o livro é referência no meio acadêmico dedicado ao jornalismo.

A segunda experiência foi o trabalho de entrevistas com 12 autores de teledramaturgia da Globo, feito em 2008, e que gerou dois volumes do livro Autores: histórias da teledramaturgia, lançado pela Globo Livros. Diferente da anterior, essa publicação reproduziu as entrevistas na íntegra, buscando preservar os aspectos informativos, o estilo, as ênfases e as nuances da fala. Por se tratar de um impresso, a limitação de espaço impôs-se e interferiu na edição da entrevista. Foi necessário reduzir aspectos da oralidade, como repetições e vícios de linguagem. Apesar da impossibilidade de reproduzir silêncios, gestos, olhares, sorrisos, hesitações e lapsos, o resultado é uma fonte rica em possibilidades para a compreensão do universo de criação na teledramaturgia.

Todas as entrevistas seguem certo padrão: trajetórias de vida que, a partir de um determinado momento, cruzam a história da teledramaturgia da Globo. Ainda que algumas perguntas se repitam, percebe-se a dinâmica singular de cada depoimento. Há autores que se detêm a falar sobre o processo de criação, outros estendem-se na recepção do público a suas obras; alguns enfatizam as características dos personagens, outros falam dos diversos estilos adotados. $\mathrm{E}$, dependendo dos temas que ganham maior relevância, a entrevista adquire um ritmo próprio.

Chama atenção a definição que fazem da teledramaturgia: um gênero baseado no melodrama, do qual a polarização entre o bem e o mal, a ênfase no sentimentalismo e no mundo subjetivo, a eloquência repetitiva na expressão de julgamentos são as principais marcas. 0 estilo hiperbólico de tratar os temas, típico dos enredos melodramáticos, mistura-se aos dramas do cotidiano. Um realismo quase naturalista, que busca "imitar a vida", mescla-se com um sentimentalismo intenso e reações exageradas. Muitos autores afirmam se inspirar em notícias de jornais e em casos reais para construir suas tramas, ao mesmo tempo em que se referem aos tipos melodramáticos (o vilão, a mocinha, o vingador, a vítima) para definir 
os personagens. Em alguns casos, aparecem na obra depoimentos de pessoas que viveram histórias semelhantes às dos personagens: é a ficção mesclando-se à realidade na narrativa. Essa "carpintaria", que revela um hibridismo entre os estilos melodramático, realista e naturalista, é identificada pelos autores. Há uma unidade indivisível das entrevistas, uma narrativa uniforme capaz de informar sobre uma experiência ao mesmo tempo individual e coletiva (Alberti, 2004: 110).

A terceira experiência foi audiovisual. Em 2013 e 2014 foram produzidos 150 minidocumentários sobre a história da Globo e 20 sobre Roberto Marinho. Esses vídeos foram disponibilizados em sites e exposições e exibidos em programas. Os documentários sobre a emissora foram divididos nos temas: coberturas jornalísticas, esportes, dramaturgia, humor, variedades, programas de auditório e reality shows. Os que trataram da trajetória de Roberto Marinho abordaram as empresas 0 Globo, Rádio Globo/Central Brasileira de Notícias (CBN), Editora Globo, Rede Globo, GloboSat e Fundação Roberto Marinho, além de aspectos mais pessoais, como a infância e a vida familiar, a paixão pelos esportes, a formação da coleção de artes e o apoio a iniciativas culturais. 0 formato entrelaçou depoimentos com imagens de arquivo.

Esse trabalho suscitou uma série de questões sobre a força da imagem para revelar um acontecimento ou expressar um pensamento. Um aspecto merece destaque: o uso dos depoimentos em produções audiovisuais permite capturar a atmosfera da entrevista, assim como aspectos mais subjetivos: tristeza, alegria, surpresa, excitação, frustração, hesitações, dúvidas, enfim, reações e expressões impossíveis de serem transpostas para uma publicação impressa. Nesse sentido, ainda que sujeita a inúmeras questões relativas à edição de imagem e som, uma produção audiovisual tem o potencial de trabalhar com entrevistas de história oral de forma mais ampla, lidando com as experiências e os acontecimentos relatados, mas também com a subjetividade que sublinha os conteúdos.

\section{OS DESAFIOS CONTEMPORÂNEOS DA HISTÓRIA ORAL NA MEMÓRIA EMPRESARIAL}

$\mathrm{N}$ a sociedade da informação, o problema central não é mais a guarda e a preservação de acervos - mesmo que esse ainda seja um tema importante - mas o excesso de dados disponíveis. Com tecnologias acessíveis e baratas, a realização de entrevistas e a montagem de programas de história oral não apresentam mais a complexidade de antes nem demandam o mesmo investimento de recursos por parte das empresas. A digitalização eliminou o uso de fita, discos óticos e outros dispositivos materiais e amenizou o problema de espaço e lugar para o armazenamento físico desses materiais. 
As tarefas daqueles que trabalham em áreas de memória nas empresas, por outro lado, aumentaram muito em complexidade no contexto das mídias digitais e em rede. Ganharam relevo processos de seleção, atribuição de relevância, análise e mesmo descarte. Hoje, talvez a questão mais importante seja o que fazer com os acervos que os programas de história oral geram nas empresas. Quais são seus usos potenciais? Apresentamos três exemplos com base na experiência do Grupo Globo. Mas que outras possibilidades existem? Ao longo de seus 22 anos de existência, a área de memória da Globo produziu um acervo grande e rico em potencialidades. Ainda que tenha gerado produtos exitosos para a empresa e para a sociedade, sabemos que há um campo vasto ainda inexplorado.

Comparando a experiência da Globo com a de outros grupos empresariais, muitas questões nos vêm à cabeça. Será que os depoimentos produzidos em grande quantidade nos contextos empresariais têm sido subutilizados? Observamos que têm sido gerados acervos grandes, mas pouco dinâmicos, pouco vivos e raramente integrados aos processos das empresas. Ficamos pensando até que ponto a montagem de programas de história oral não tem sido impulsionada por uma espécie de fetiche pela entrevista, pelo impulso ao registro que caracteriza o tempo em que vivemos ou simplesmente pela valorização da subjetividade e dos relatos biográficos do ambiente cultural em que estamos inseridos.

São muitos os desafios colocados hoje para as áreas de memória e para a história oral nas empresas. 0 século XXI trouxe uma série de transformações na vida dos indivíduos e das sociedades em geral. As empresas também se viram diante de um turbilhão de mudanças que as obrigam a repensar suas atividades, seus valores, suas estratégias. Inovações tecnológicas fazem com que a automação e a tecnologia da informação ganhem ritmo acelerado. A robótica, a inteligência artificial, a hiperconectividade, o armazenamento de dados em nuvens, a manufatura aditiva, as biotecnologias fazem com que as empresas repensem seus processos e mesmo seus produtos.

Paralelamente, os grupos empresariais veem-se diante de consumidores mais exigentes, que buscam maior sintonia com os produtos que consomem. A adoção de boas práticas ambientais, sociais e de governança torna-se um diferencial competitivo essencial para o reconhecimento público. As conquistas dos movimentos identitários impuseram o desafio de dar mais diversidade ao corpo de funcionários, levando as áreas de recursos humanos a se empenharem em novos processos seletivos e estratégias de crescimento profissional de modo a criarem oportunidades maiores para grupos sociais historicamente excluídos. As organizações procuram investir em estruturas menos hierárquicas e mais participativas, em novas formas de trabalhar e avaliar competências, no maior compartilhamento de informações e decisões. A transformação da cultura empresarial é uma necessidade urgente para que as organizações se reposicionem em um mundo mais veloz, dinâmico, volátil e em permanente transformação. 
Diante desse cenário desafiador, as estratégias e os recursos das empresas direcionam-se para ações e projetos voltados para o presente e para o futuro, em sintonia com as transformações do mercado. Nesse contexto, qual seria o sentido de trabalhar a história empresarial? Até que ponto pensar sobre o passado amplia a compreensão do presente e ajuda a desenhar direções futuras? Em que medida programas de história oral em centros de memória empresarial podem contribuir com o negócio e sua redefinição em um mundo em permanente mudança? Qual a motivação das empresas para investir nesse tipo de programa, mobilizando colaboradores e disponibilizando condições físicas e equipamentos para a realização das entrevistas? Por que produzir milhares de horas de gravação e arquivá-las em bancos de dados?

Empresas no mundo inteiro têm recorrido ao passado para enfrentar os desafios contemporâneos. A busca pelas experiências vividas tem o potencial de ampliar ou redimensionar o campo de atuação das organizações, ajudando na releitura dos seus valores e na autoavaliação nos momentos de crise. Episódios registrados negativamente na memória social podem ser submetidos a análise crítica e contribuir para a identificação de erros e acertos, dando pistas para elaboração de novas práticas. A história oral pode ser uma ferramenta poderosa para identificar, no passado, elementos com potencial de elucidar o presente e apontar rumos futuros. As dimensões subjetivas e objetivas de uma entrevista podem fornecer elementos significativos para trabalhar com os valores e a cultura empresarial.

Na entrevista, o que está em foco é a biografia do entrevistado, sua percepção enquanto indivíduo singular. É sua identidade individual que é enfatizada. Mas também estão em jogo seus papéis sociais, sua aderência às diversas identidades: aquelas já dadas, como família, grupo étnico, geração, situação social, e as adquiridas em função de opções e escolhas, como profissão, relações de amizade, grupo político e orientação religiosa (Velho, 2003). Entra também em cena a identidade da empresa: os valores, as crenças, os princípios e as opções mercadológicas que dão sentido à corporação. Em algumas circunstâncias essas identidades se harmonizam; em outras podem estar em conflito.

0 conceito sociológico de projeto desenvolvido por Schutz (1979) e extensamente trabalhado por Velho (1981) pode ser uma chave interessante para compreender o potencial da história oral na redefinição da cultura empresarial. Os autores constatam que, nas sociedades moderno-contemporâneas, complexas e heterogêneas, há forte ênfase na noção de indivíduo sujeito singular, psicológico, que exerce uma multiplicidade de papéis. Ainda que a tensão entre indivíduo, instituição e sociedade permaneça em muitos momentos, impõe-se a ideia de um indivíduo dotado de uma biografia particular, que tem preferências, peculiaridades e que faz opções e escolhas. 
0 conceito de projeto, entendido como ação com objetivo predeterminado, construído em função de experiências socioculturais e elaborado em meio a um campo de possibilidades, ajuda a pensar a entrevista de história oral no contexto empresarial. 0 projeto traduz a originalidade da experiência individual. Mesmo que sejam vividas como únicas, as ideias, as condutas e as ações de um indivíduo estão sempre localizadas no tempo e no espaço (VeIho, 2003: 103). Quando um grupo de indivíduos tem projetos comuns, vivências, visões e objetivos semelhantes, pode-se afirmar que há um projeto social que engloba, incorpora ou sintetiza os projetos individuais. Nesse sentido, podemos dizer que a entrevista de história oral em uma empresa transita por esses dois caminhos, ora enfatizando projetos individuais, ora dando relevo ao projeto institucional e social globalizante.

Aqui está um dos principais potenciais de programas empresariais de história oral: tornar públicas biografias e múltiplos projetos individuais que, em seu conjunto, podem constituir uma polifonia, um jogo contrapontual de vozes. Ao revisitar os diferentes momentos vividos pelo colaborador e pela empresa, os princípios e valores em jogo e os comportamentos adotados em diversos contextos, a história oral pode revelar aquilo que deve ser fortalecido, ressignificado e radicalmente alterado. Trata-se de um caminho fértil para a redefinição da cultura empresarial e das suas estratégias de atuação diante de um mundo em permanente transformação.

Conflitos de interesse: nada a declarar.

Fonte de financiamento: nenhuma.

Contribuições das autoras: Ribeiro, A. P. G.; Fiuza, S.: Administração do Projeto, Análise Formal, Conceituação, Curadoria de Dados, Escrita — Primeira Redação, Escrita — Revisão e Edição, Recursos, Software, Supervisão, Validação e Visualização.

\section{REFERÊNCIAS BIBLIOGRÁFICAS}

ALBERTI, V. História oral: a experiência do CPDOC. Rio de Janeiro: Editora FGV, 1989.

ALBERTI, V. Vender história? A posição do CPDOC no mercado das memórias. Rio de Janeiro: CPDOC, 1996. ALBERTI, V. Ouvir contar: textos em história oral. Rio de Janeiro: Editora FGV, 2004.

ARFUCH, B. S. L. La entrevista, una invención dialógica. Buenos Aires: Editora Paidós, 1995.

BLOCH, M. História e historiadores: texto reunidos por Étienne Bloch. Lisboa: Editorial Teorema, 1998.

BOURDIEU, P. A ilusão biográfica. In: FERREIRA, M. M.; AMADO, J. Usos e abusos da história oral. Rio de Janeiro: Editora FGV, 2006. p. 183. 
FIUZA, S. (org.). Jornal Nacional: a notícia faz história. Rio de Janeiro: Jorge Zahar, 2004. Memória Globo.

FIUZA, S. (org.). Autores: histórias da teledramaturgia. São Paulo: Globo Livros, 2008. Memória Globo.

GEERTZ, C. A interpretação das culturas. Rio de Janeiro: Zahar Editores, 1978.

GOFFMAN, E. Os quadros da experiência social: uma perspectiva de análise. Petrópolis: Editora Vozes, 2012.

HALBWACHS, M. A memória coletiva. São Paulo: Editora Vértice, 1990.

HUYSSEN, A. Seduzidos pela memória. Rio de Janeiro: Aeroplano, 2000.

JOUTARD, P. Desafios à história oral do século XXI. In: FERREIRA, M. M.; FERNANDES, T. M.; ALBERTI, V. (orgs.). História oral: desafios para o século XXI. Rio de Janeiro: Editora Fiocruz/FGV, 2000. p. 31.

JOUTARD, P. Reconciliar história e memória? Escritos: Revista da Fundação Casa de Rui Barbosa, Rio de Janeiro, ano 1, n. 1, p. 223-235, 2007.

JOUTARD, P. Histoire et mémoires: conflits et alliance. Paris: Éditions la Découverte, 2015.

KEIGHTLEY, E.; PICKERING, M. The Mnemonic Imagination: remembering as creative practice. Londres: Palgrave Macmillan, 2012.

KERWIN, L. K. On the Emergence of Memory in Historical Discourse. Representation, Hoboken, n. 69, p. 127-150, 2000. https://doi.org/10.2307/2902903.

POLLAK, M. Memória, esquecimento, silêncio. Estudos Históricos, Rio de Janeiro, v. 2, n. 3, p. 3-15, 1989.

POLLAK, M. Memória e identidade social. Estudos Históricos, Rio de Janeiro, v. 5, n. 10, p. 200-215, 1992.

PORTELLI, A. O massacre de Civitella Val di Chiana. In: FERREIRA, M. M.; AMADO, J. Usos e abusos da história oral. Rio de Janeiro: Editora FGV, 2006. p. 103.

SARLO, B. Tempo passado: cultura da memória e guinada subjetiva. São Paulo: Belo Horizonte: Companhia das Letras, UFMG, 2007.

SCHUTZ, A. Fenomenologia e relações sociais. Rio de Janeiro: Zahar Editores, 1979.

THOMSON, A.; FRISCH, M.; HAMILTON, P. Os debates sobre memória e história: alguns aspectos internacionais. In: AMADO, J.; FERREIRA, M. M. (orgs.). História oral: desafios para o século XXI. Rio de Janeiro: Editora FGV, 2005. p. 65.

TRILLING, L. Sinceridade e Autenticidade: a vida em sociedade e a afirmação do Eu. São Paulo: É Realizações Editora, 2014.

VELHO, G. Indivíduo e sociedade: notas para uma antropologia da sociedade contemporânea. Rio de Janeiro: Zahar Editores, 1981.

VELHO, G. Projeto e metamorfose: antropologia das sociedades complexas. Rio de Janeiro: Jorge Zahar, 2003. WIEVIORKA, A. L'Ėre du témoin. Paris: Plon, 1995. 